\title{
Periampullary Adenocarcinoma
}

National Cancer Institute

\section{Source}

National Cancer Institute. Periampullary Adenocarcinoma. NCI Thesaurus. Code C27322.

An adenocarcinoma that arises from the periampullary region. 